\title{
Effect of Spin Coating Speed on Some Optical Properties of ZnO Thin Films
}

\author{
David Adegboyega Ajadi, Saint Muyiwa Agboola, Oluwaseun Adedokun* \\ Department of Pure and Applied Physics, Ladoke Akintola University of Technology, Ogbomoso, Nigeria \\ Email: oadedokun@lautech.edu.ng, "adedokunoluwaseun2@gmail.com
}

Received 5 February 2016; accepted 20 May 2016; published 23 May 2016

Copyright @ 2016 by authors and Scientific Research Publishing Inc.

This work is licensed under the Creative Commons Attribution International License (CC BY). http://creativecommons.org/licenses/by/4.0/

(c) (i) Open Access

\begin{abstract}
This paper reports the synthesis and characterization of $\mathrm{ZnO}$ thin films prepared by sol-gel spin coating technique. The sol-gel was prepared from zinc acetate dehydrate as a precursor, 2-methoxyethanol as a solvent and di-ethanolamine as a stabilizer, and then deposited on glass substrate using spin coater at the coating speed of $1000 \mathrm{rpm}, 2000 \mathrm{rpm}, 3000 \mathrm{rpm}, 4000 \mathrm{rpm}, 5000$ rpm and $6000 \mathrm{rpm}$. After pre-heated at $150^{\circ} \mathrm{C}$, the samples were post-heated at $250^{\circ} \mathrm{C}$ and also annealed at $400^{\circ} \mathrm{C}$. X-ray diffraction (XRD) of the films showed polycrystalline hexagonal structure, with (002) orientation as most intense peak having a grain size of $28.1 \mathrm{~nm}$. The absorbance of the film decreases with increasing wavelength and the transmittance was generally high between visible regions from $280 \mathrm{~nm}-1200 \mathrm{~nm}$. The $\mathrm{ZnO}$ films deposited at a spinning speed of $2000 \mathrm{rpm}$ had highest transmittance of $88 \%$ in the visible region from $280 \mathrm{~nm}-1200 \mathrm{~nm}$. The energy band gap was found to be in the range of $3.23-3.40 \mathrm{eV}$. The thicknesses of the films decreased with increase in coating speed. Based on these results, $\mathrm{ZnO}$ thin films obtained could have useful application in transparent conducting oxide electrode in solar cells.
\end{abstract}

\section{Keywords}

Sol-Gel Spin Coating Technique, Annealing, Grain Size, XRD, Energy Band Gap

\section{Introduction}

Zinc oxide is an inexpensive n-type semiconductor having direct energy band gap of $3.37 \mathrm{eV}$ which is in two main forms, hexagonal wurtzite ( $a=3.25 \AA$ and $c=5.2 \AA$ ) [1] and cubic zincblende structure. ZnO has also being widely used as an additive in numerous materials and products including plastics, ceramics, glass, cement, lubricants, paints, ointments, adhesives, sealants, pigments, foods (source of $\mathrm{Zn}$ nutrient), batteries, ferrites, fire

"Corresponding author.

How to cite this paper: Ajadi, D.A., Agboola, S.M. and Adedokun, O. (2016) Effect of Spin Coating Speed on Some Optical Properties of ZnO Thin Films. Journal of Materials Science and Chemical Engineering, 4, 1-6.

http://dx.doi.org/10.4236/msce.2016.45001 
retardants and first aid tapes. Thin films of Zinc oxide can be prepared by various techniques; among them are Sputtering [2], Chemical Vapor Deposition (CVD) [3], Laser ablation [4], Sol-gel [5] [6], Spray pyrolysis [7]. The sol-gel spin coating has advantages such as easy control of chemical composition, ability to produce fine structure and fabrication of thin film at low cost. Relatively few works have been done in this direction for $\mathrm{ZnO}$ film prepared by sol-gel process [7]. However, adopting spin coating technique can result in growth of a structurally, optically and electrically promising $\mathrm{ZnO}$ thin film with appreciable energy band gap. This can partner some other semiconductor materials in improving photovoltaic technology.

Effect of spin coating speed and other deposition parameters on crystalline sizes of $\mathrm{ZnO}$ thin films have been reported [8].

In the present work, $\mathrm{ZnO}$ films are obtained by sol-gel spin coating technique, its structures are verified and the effect of spin coating speed on some optical properties is studied using X-ray diffractometer and UV-Vis spectroscopy.

\section{Experimental Procedure}

The glass slides $(2.5 \mathrm{~cm} \times 2.5 \mathrm{~cm})$ were washed with an alkali-free detergent and rinsed many times in distilled water then the ultrasonic cleaning of the glass substrates in acetone and methanol and finally the substrate was dry in an oven.

The sol-gel solution were prepared by dissolving $6.5 \mathrm{~g}$ of zinc acetate dehydrate in $10 \mathrm{ml}$ of 2-methoxyethanol and stirred continuously for 30 minutes at $60^{\circ} \mathrm{C}$ until the solution become turbid, di-ethanolamine was added drop by drop under constant stirring until the turbid or milky solution was cleared. The resultant solution was stirred continuously for another 90 minutes until a colorless, homogeneous and transparent solution was obtained. The solution was kept for 72 hours at room temperature for aging and also for optimum viscosity to be obtained.

The sol-gel solution was dropped onto glass substrate, which was rotated at different spin coating speed of $1000 \mathrm{rpm}, 2000 \mathrm{rpm}, 3000 \mathrm{rpm}, 4000 \mathrm{rpm}, 5000 \mathrm{rpm}$ and $6000 \mathrm{rpm}$ for $30 \mathrm{~s}$ each by using LAURELL WS-4006NPPSS spin coater. After the deposition, the films were pre heated at $150^{\circ} \mathrm{C}$ for 3 hours immediately after coating and post heated at $250^{\circ} \mathrm{C}$ for 6hours in an oven to evaporate the solvent and remove organic residues. The films were then inserted into a crucible and annealed in air at $400^{\circ} \mathrm{C}$ for 4 hours. The flow chart showing the procedure for preparing $\mathrm{ZnO}$ thin films were shown in Figure 1. The thicknesses of the films were measured with profiler. X-ray diffraction patterns were obtained with a PanalyticalXpert Pro, XRD using the CuKa radiations $\left(\lambda=1.54059 \AA\right.$ ) in the range of $2 \theta$ between $10^{\circ}$ and $100^{\circ}$. The optical measurement of the film was carried out at room temperature using Jenway $6405 \mathrm{UV} / \mathrm{Vis}$, spectrophotometer with the wavelength range from $280 \mathrm{~nm}$ to $1200 \mathrm{~nm}$.

\section{Results and Discussions}

\subsection{Structural Analysis of Polycrystalline Films}

The crystal structure of ZnO film prepared by sol-gel process was investigated through X-ray diffraction (XRD). Figure 2 shows XRD pattern of $\mathrm{ZnO}$ thin film deposited on glass substrate and annealed at $400^{\circ} \mathrm{C}$. The prominent reflection peaks show that the film is polycrystalline in nature. The lattice constants " $a$ " and " $c$ " of the hexagonal wurtzite structure of $\mathrm{ZnO}$ film with (002) orientation can be calculated using Equations (1) and (2) [9].

$$
\begin{aligned}
& a=\frac{\sqrt{\frac{1}{3 \lambda}}}{\sin \theta} \\
& c=\frac{\lambda}{\cos \theta}
\end{aligned}
$$

where $\lambda$ is the wavelength of the radiation and $\theta$ is the Bragg's angle. The values obtained for the unit cell $a=$ $3.020 \AA$ and $c=5.108 \AA$ are in good agreement with those reported in the literature. The diffraction peaks correspond to the crystallographic orientations (100), (002), (101) at angles $2 \theta=28.006^{\circ}, 30.15^{\circ}$ and $32.962^{\circ}$ respectively. 


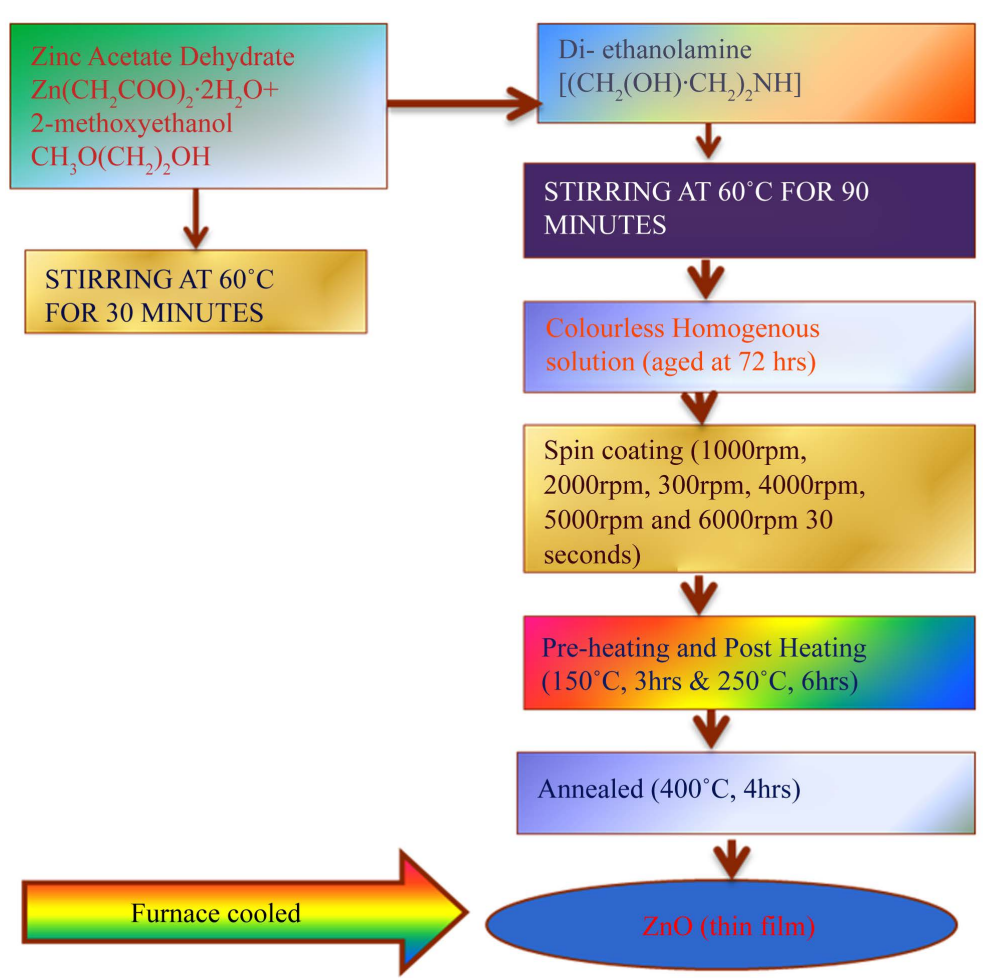

Figure 1. The flow chart for the procedure for preparing $\mathrm{ZnO}$ thin films.

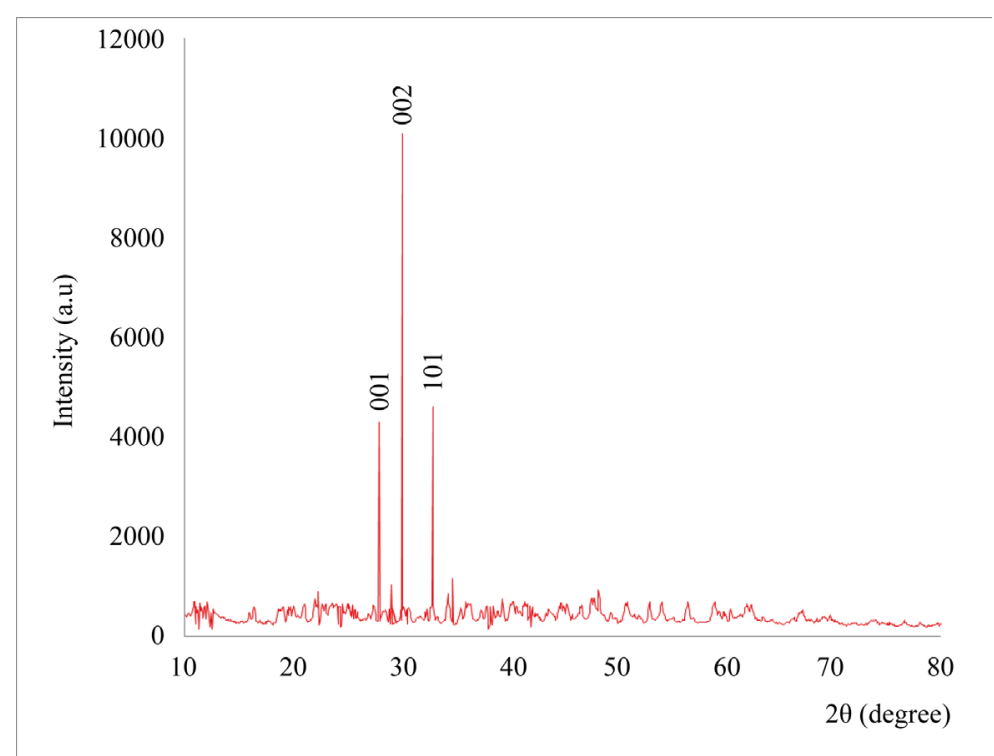

Figure 2. XRD pattern for $\mathrm{ZnO}$ thin film annealed at $400^{\circ} \mathrm{C}$.

From the XRD spectrum, grain size (D) of the film was calculated using the Debye Scherrer's formula [9]:

$$
D_{h k l}=\frac{K \lambda}{\beta \cos \theta}
$$

where $k$ is a constant to be taken $0.9, \beta$ is Full Width Half Maximum (FWHM) in radian, $\lambda$ is the wavelength of $\mathrm{X}$-ray used and $\theta$ is Bragg's angle. The grain size of (002) oriented thin film was calculated to be $28.1 \mathrm{~nm}$. This is very close to the result reported by [7]. 


\subsection{Optical Properties of Polycrystalline ZnO Thin Films}

The films thicknesses were measured to be between $127.4 \mathrm{~nm}$ and $81.5 \mathrm{~nm}$. The thickness of the film becomes thinner as the spin coating speed increases then the fluid spins off rapidly at the surface of the substrate at a higher coating speed.

Figure 3 displays the optical transmittance spectrum of polycrystalline $\mathrm{ZnO}$ thin films annealed at $400^{\circ} \mathrm{C}$ in air for 4 hours using UV-spectrophotometer from $200 \mathrm{~nm}-1200 \mathrm{~nm}$ for different coating speed. It can be seen that the transmission values of the film are low at short wavelengths $(<380 \mathrm{~nm})$ and high at long wavelengths. This implies that the film behaved as a transparent material at long wavelengths. The average transmittance value is $80 \%$ in both $2000 \mathrm{rpm}$ and $3000 \mathrm{rpm}$ samples; this indicates that the film could be used as transparent conducting oxide electrode for solar cell which is similar to reported work of Ali et al. [10]. But in $4000 \mathrm{rpm}, 5000 \mathrm{rpm}$ and 6000 rpm samples, the transmittance reduced to $60 \%$. The existence of the interference patterns in the transmittance spectra is due to the film thickness. The interference through the film happens when light reflected from the top surface of a film at specific wavelength and from the bottom of the film at other wavelength. Construction and destruction of wave occur whenever light reflects off a surface of higher refractive index.

Figure 4 displays the absorption spectra for the films at different coating speed, the absorbance of the films decreases with increasing wavelength and decreasing photon energy. For each samples, there is an absorption level that do not differ from one another, their sharp absorption edge is located at $380 \mathrm{~nm}$ which is due to the

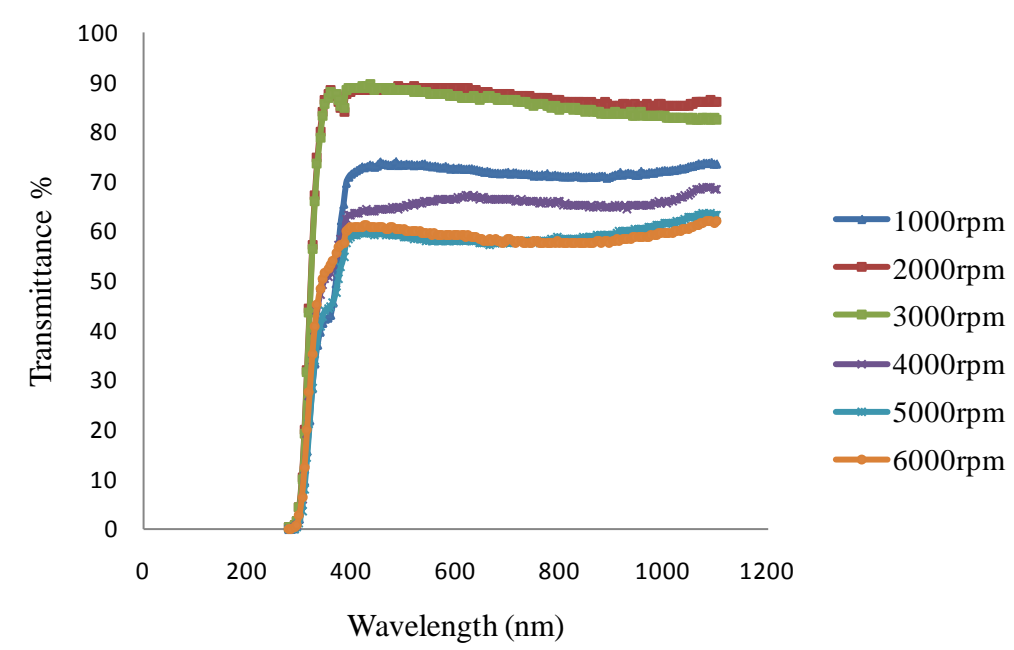

Figure 3. The transmittance spectra for $\mathrm{ZnO}$ films at different coating speed.

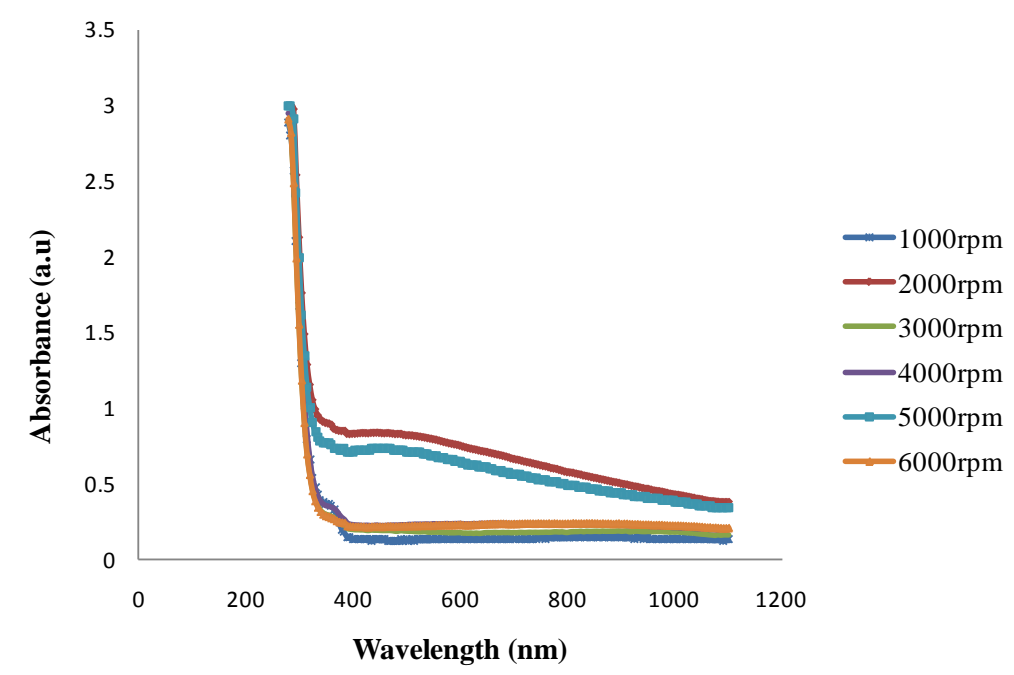

Figure 4. The absorption spectra for $\mathrm{ZnO}$ thin films at different coating speed. 
fact that the $\mathrm{ZnO}$ is a direct band gap semiconductor. The absorption spectrum of the $\mathrm{ZnO}$ films also reveals that the film has low absorbance in the visible and near infrared regions, while absorbance is high in the ultra violet region.

The energy band gap, $E_{g}$ of the prepared $\mathrm{ZnO}$ thin film can be determined from the graph of $(\alpha h v)^{2}$ against photon energy. The values of $E_{g}$ change with spin coating speed which show in Figure 5. The corresponding optical band gap of $\mathrm{ZnO}$ thin film was estimated by extrapolation of the linear relationship between $(\alpha h v)^{2}$ and hv according to the Equation (4).

$$
\alpha h v=A\left(h v-E_{g}\right)^{1 / 2}
$$

where $\alpha$ is the absorption coefficient, $h v$ is the photon energy, $E_{g}$ is the optical band gap and $A$ is a constant.

Figure 5 depicts the energy band gap value for $\mathrm{ZnO}$ thin film which varies from $3.23 \mathrm{eV}-3.40 \mathrm{eV}$ which is very close to work done by Ilican et al. [7]. The slight deviation in the energy band gap from this work compared with the previous work [7] [10] [11] may be due to the fact that the values of band gap depend on many factors likecoating speed (rpm), the granular structure, the nature and concentration of precursors, the structural defects and the crystal structure of the films. The band gap difference between the film and bulk $\mathrm{ZnO}$ is due to the grain boundary, the stress and the interaction potentials between defects and the host materials in the films [12].

The films thickness and value of $E_{g}$ at different coating speed is shown in Table 1.

\section{Conclusion}

A high quality $\mathrm{ZnO}$ thin film on glass substrate has been prepared by sol-gel method using spin coating tech-

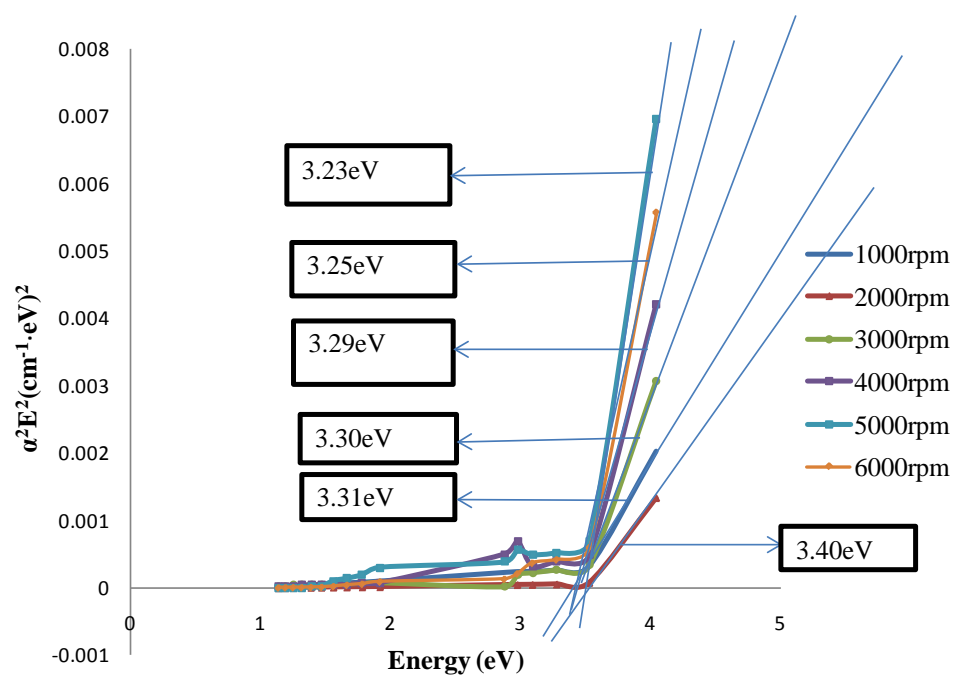

Figure 5. The energy band bap of $\mathrm{ZnO}$ thin films at different coating speed.

Table 1. The films thickness and energy band gap of $\mathrm{ZnO}$ thin films at different coating speed.

\begin{tabular}{ccc}
\hline $\begin{array}{c}\text { Spin Coating Speed } \\
(\mathrm{rpm})\end{array}$ & $\begin{array}{c}\text { Thickness } \\
(\mathrm{nm})\end{array}$ & $\begin{array}{c}\text { Energy Band Gap } \\
(\mathrm{eV})\end{array}$ \\
\hline 1000 & 127.40 & 3.31 \\
2000 & 109.10 & 3.40 \\
3000 & 97.60 & 3.30 \\
4000 & 91.30 & 3.29 \\
5000 & 84.70 & 3.23 \\
6000 & 81.50 & 3.25 \\
\hline
\end{tabular}


nique and also structural and optical properties are verified. The XRD spectrum indicates that the films are of polycrystalline structure with intense peak of (002) orientation. The thickness of the film becomes thinner as the coating speed increase. The average optical transmittance for $2000 \mathrm{rpm}$ and $3000 \mathrm{rpm}$ samples are $80 \%$ and their energy band gap is very close to the bulk $\mathrm{ZnO}(3.37 \mathrm{eV})$. This present research shows that high transmittance can be achieved at the spin coating speed of $2000 \mathrm{rpm}$ to $3000 \mathrm{rpm}$ which can be used as transparent conducting oxide electrodes. Further work should be done on the effect of other optical properties (like refractive index, extinction coefficient and reflectance) and annealing temperature on spin coated $\mathrm{ZnO}$ thin film.

\section{Acknowledgements}

The authors acknowledge the effort of R\&D Laboratory, Engineering Materials Development Institute, Akure, Nigeria for film deposition and optical measurements and also Physics Advanced Laboratory, Sheda Science and Technology Complex, Abuja, Nigeria for XRD characterization.

\section{References}

[1] Fierro, J.L.G. (2006) Metal Oxides: Chemistry \& Applications. 6000 Broken Sound Parkway NW, Suite 300, Taylor \& Francis Group.

[2] Moustaghfir, A., Tomasella, E., Ben Amor, S., Jacquet, M., Cellier, J. and Sauvage, T. (2003) Structural and Optical Studies of ZnO Thin Films Deposited by RF. Magnetron Sputtering: Influence of Annealing. Surface and Coatings Technology, 174-175, 193-196.

[3] Haga, K., Kamidaira, M., Kashiwaba, Y., Sekiguchi, T. and Watanabe, H. (2000) ZnO Thin Films Prepared by Remote Plasma-Enhanced CVD Method. Journal of Crystal Growth, 214, 77-80. http://dx.doi.org/10.1016/S0022-0248(00)00068-3

[4] Narasimhan, K.L., Pai, S.P., Palkar, V.R. and Pinto, R. (1997) High Quality Zinc Oxide Films by Pulsed Laser Ablation. Thin Solid Films, 295, 104-106. http://dx.doi.org/10.1016/S0040-6090(96)09157-2

[5] Bao, D., Gu, H. and Kuang, A. (1998) Sol-Gel Derived c-Axis Oriented ZnO Thin Films. Thin Solid Films, 132, 37-39. http://dx.doi.org/10.1016/S0040-6090(97)00302-7

[6] Inoguchi, M., Suzuki, K., Tanaka, N., Kageyama, K. and Takagi, H. (2009) Structural and Optical Properties of Nanocrystalline ZnO Thin Films Derived from Clear Emulsion of Monodispersed ZnO Nanocrystals. Journal of Materials Research, 24, 2243-2251. http://dx.doi.org/10.1557/jmr.2009.0277

[7] Ilican, S., Caglar, Y. and Caglar, M. (2008) Preparation and Characterization of ZnO Thin Films Deposited by Sol-Gel Spin Coating Method. Journal of Optoelectronics and Advanced Materials, 10, 2578-2583.

[8] Aqeel, A.A., Safaa, M.H. and Ali, H.A. (2013) The Effect of Spin Coating Speed and Deposition Parameters on the Crystalline Size of ZnO Thin Films. Diyala Journal of Engineering Sciences, 6, 100-106.

[9] Saleem, M., Fang, L., Wakeel, A., Rashad, M. and Kong, C. (2012) Simple Preparation and Characterization of Nano-Crystalline Zinc Oxide Thin Films by Sol-Gel Method on Glass Substrate. World Journal of Condensed Matter Physics, 2, 10-15. http://dx.doi.org/10.4236/wjcmp.2012.21002

[10] Ali, F., Abdul, R., Suganthi, D., Sanjeeviraja, C. and Swaminathan, V. (2011) Effect of Annealing on Structural and Optical Properties of ZnO Thin Films by Sol-Gel Technique. Chalcogenide Letters, 8, 511-519.

[11] Shariffudin, S.S., Salina, M. and Herma, S.H. (2012) Effect of Film Thickness on Structural, Electrical, and Optical Properties of Sol-Gel Deposited Layer-by-layer ZnO Nanoparticles. Transaction on Electrical and Electronic Materials, 13, 102-105. http://dx.doi.org/10.4313/TEEM.2012.13.2.102

[12] Zhang, D.L., Zhang, J.B., Wu, Q.M. and Miao, X.S. (2010) Microstructure, Morphology, and Ultraviolet Emission of Zinc Oxide Nanopolycrystalline Films by the Modified Successive Ionic Layer Adsorption and Reaction Method. Journal of the American Ceramic Society, 93, 3284-3290. http://dx.doi.org/10.1111/j.1551-2916.2010.03846.x 